\title{
Wireless induction coils embedded in diamond for power transfer in medical implants
}

\author{
Md. Kabir Uddin Sikder ${ }^{1,2,4}$ • James Fallon ${ }^{1,2,5} \cdot$ Mohit N. Shivdasani ${ }^{1,2} \cdot$ Kumaravelu \\ Ganesan $^{3} \cdot$ Peter Seligman $^{2} \cdot$ David J. Garrett ${ }^{2,3,6}$ \\ ${ }^{1}$ Department of Medical Bionics, The University of Melbourne, Parkville, Melbourne, VIC 3010 \\ ${ }^{2}$ Bionics Institute, 384 Albert St, East Melbourne, VIC 3002 \\ ${ }^{3}$ Department of Physics, The University of Melbourne, Parkville, Melbourne, VIC 3010 \\ ${ }^{4}$ Department of Physics, Jahangirnagar University, Savar, Dhaka 1342, Bangladesh \\ ${ }^{5}$ Department of Otolaryngology, The University of Melbourne, Parkville, Melbourne, VIC 3010
}

\begin{abstract}
Wireless power and data transfer to medical implants is a research area where improvements in current state-of-the-art technologies are needed owing to the continuing efforts for miniaturization. At present, lithographical patterning of evaporated metals is widely used for miniature coil fabrication. This method produces coils that are limited to low micron or nanometer thicknesses leading to high impedance values and thus limiting their potential quality. In the present work we describe a novel technique, whereby trenches were milled into a diamond substrate and filled with silver active braze alloy, enabling the manufacture of small, high cross-section, low impedance microcoils capable of transferring up to $10 \mathrm{~mW}$ of power up to a distance of $6 \mathrm{~mm}$. As a substitute for a metallic braze line used for hermetic sealing, a continuous metal loop when placed parallel and close to the coil surface reduced power transfer efficiency by $43 \%$, but not significantly, when placed perpendicular to the microcoil surface. Encapsulation of the coil by growth of a further layer of diamond reduced the quality factor by an average of $38 \%$, which can be largely avoided by prior oxygen plasma treatment. Furthermore, an accelerated ageing test after encapsulation showed that these coils are long lasting. Our results thus collectively highlight the feasibility of fabricating a high-cross section, biocompatible and long lasting miniaturized microcoil that could be used in either a neural recording or neuromuscular stimulation device.
\end{abstract}

\section{Key words}

Medical implant $\cdot$ Wireless power $\cdot$ Diamond $\cdot$ Braze $\cdot$ Silver ABA $\cdot$ Induction coil

${ }^{6}$ Correspondence: David J Garrett, E-mail: dgarrett@unimelb.edu.au, Address: Department of Physics, The University of Melbourne, Parkville, Melbourne, VIC 3010, Mobile: +61403353730 


\section{Introduction}

Medical bionics is the branch of medical science and technology that deals with intractable and incurable medical conditions to reduce their severity or provide therapeutic treatment using prosthetic and neuromodulation devices. The field has significant market potential owing to a wide range of diseases that the technology can target (Cavuoto 2011; Clark 2003; Shepherd et al. 2013). A number of medical implants are very commonly used, such as cochlear implants, intravascular stents, deep brain stimulators and visual prostheses. One notable trend is the increase in the emergence of artificial neural implants that either record from, or electrically stimulate, peripheral or central neurons.

In order to perform this function, implants require a continuous, efficient power supply (Amato et al. 2013) that would preferably transmit power wirelessly, thus minimizing the risk of infection, patient discomfort, pain, health care costs and the need for implantable batteries. Inductive power transfer is therefore a necessary technology in developing safer, more robust devices with lower risk of tissue damage caused by long periods of continuous transcutaneous connections (Amato et al. 2013; Jow and Ghovanloo 2007; Kadefors et al. 1969; Neagu et al. 1997). The efficiency of wireless power-transfer however, strongly depends on a variety of parameters such as, the materials used, coupling and distance between the transfer and receiver coils and their geometrical dimensions, for example the length and cross-section of the coil wire. Besides the outer and inner diameter of the coils, properties of the encapsulation materials influence the overall efficiency of the implant system (Amato et al. 2013). The efficiency of coils is measured by their quality factor (Q-factor), which is defined as the ratio of the electromagnetic energy transmitted $\left(\mathrm{E}_{\mathrm{tr}}\right)$ to the receiver coil and energy dissipated $\left(\mathrm{E}_{\mathrm{dis}}\right)$ through it according to Equation (1).

$$
Q=\frac{E_{t r}}{E_{d i s}}=\omega_{\circ} \frac{L}{R_{S}}
$$

Where, $\omega_{\circ}$ is the operating frequency, $L$ is inductance and $R_{s}$ is series resistance.

In cochlear and retinal implants, while inductive power transfer systems are being used, the receiver coils are large in dimension (in the centimeter range) and implanted subcutaneously behind the ear anchored to the skull (Amato et al. 2013; Jow and Ghovanloo 2007; Li et al. 2011). In recent decades, the development of microelectronics has provided opportunities for the miniaturization of neural implants. Recently, very small devices designed to be implanted within small body structures such as the eye (Ahnood et al. 2015; Ganesan 2014; Ganesan et al. 2014; Garrett et al. 2012; Hadjinicolaou et al. 2012; Lichter et al. 2015b; Maturana et al. 2016; Nayagam et al. 2015; Shivdasani 2013), or inside cortical blood vessels (Oxley et al. 2016) have been developed. The recent surge in interest in electroceuticals for treatment of a range of disorders has led to a myriad of neuromodulation targets, such as the vagus nerve, for regulation of tumour necrosis factor (TNF) associated with autoimmune diseases of the digestive system (Crohn's disease) and rheumatoid arthritis (Martelli et al. 2014; Tracey 2002). Many of these diseases are chronic and neuromodulation devices to treat them or restore sensation (such as cochlear or retinal implants) would ideally be implanted for long time periods. Such devices have the potential to offer significant quality of life improvements to users but a major challenge when devices are small and implanted distant from the skin surface, is the transfer of sufficient power to the implants to enable long term function. For these devices, it is necessary to develop a miniaturised receiver microcoil.

Most commonly, microcoils are fabricated by photolithographic methods. For very fine structures, methods such as X-ray lithography, electron-beam lithography and ion-beam lithography can be employed. Features in the range of $10 \mathrm{~nm}$ can be achieved (Broers 1995). Microcoils fabricated using these methods however, are extremely thin in cross-section resulting in high electrical resistance and the inability to deliver sufficient power inductively to the implant. Wen Li et al. designed and fabricated a two layered (each layer consisted of 10 turns) gold coil of $3 \mu \mathrm{m}$ thickness with outer diameter of $9 \mathrm{~mm}$ and inner diameter of $5 \mathrm{~mm}$ on a Parylene C coated silicon substrate via photolithography. The maximum power of about $43 \mathrm{~mW}$ could be delivered at a distance of $1 \mathrm{~mm}$ using an inductive link but the power was reduced by $62 \%$ at $2 \mathrm{~mm}$ distance due to divergence of the electromagnetic field and the delivered power reduced to $10 \mathrm{~mW}$, where the maximum detectable range was only about $4 \mathrm{~mm}$ (Li et al. 2011).

In addition to the coil design and fabrication, the material used for coil wire is also very important. The coil wire material should have high conductivity for efficient power transmission (Amato et al. 2013; Ko et al. 1977; 
Neagu et al. 1997). Various materials are being used to make coils such as gold (Li et al. 2011), gallium or gallium alloys and aluminium (Amato et al. 2013; Baj-Rossi et al. 2013). In this study, we considered the use of silver based active brazing alloy (ABA) for coil fabrication. Silver ABA is currently being used for interconnections in electronic packaging industry for their solderability (Zhu and Chung 1994) and can also serve as a metal film conductor having low electrical resistivity of $2.2 \times 10^{-8} \mathrm{ohm} . \mathrm{m}$, only $38 \%$ higher than that of pure silver $\left(1.59 \times 10^{-8} \mathrm{ohm} . \mathrm{m}\right)$. Silver ABA also produces low porosity films and has excellent film-substrate adhesion to diamond (Zhu and Chung 1994). These properties make silver ABA an attractive choice of material to fabricate a coil. However, whilst the material has some excellent properties it is unsuitable for use in medical implants without encapsulation as it exhibits very poor biocompatibility (Lichter et al. 2015a).

Effective power transfer not only requires an efficient inductive link but also requires that losses due to parasitic inductive currents induced in the encapsulation for instance be minimised. Interactions of the hermetic encapsulation of the implants with the inductive coils therefore is a design consideration for maximising clinical effectiveness and safety over the long term (Donaldson 1976; Kirsten et al. 2012; Li et al. 2010). Various materials have been investigated for encapsulation of medical implants such as parylene C (Amato et al. 2013; Chen et al. 2008; Li et al. 2011), polyimide (Bongrain et al. 2011) (Lee et al. 2011), rigid titanium boxes, silicone (Qian et al. 2011), gold ABA (Lichter et al. 2015a) and diamond (Lichter et al. 2015a). Generally, metals are preferable for hermetic sealing of electronic packages, as polymers can degrade and become porous while brittle materials such as glasses are at risk of breakage. Metals however, are electrically conductive effectively forming a 'short-circuited turn' adjacent to the coils when inductive power is transferred to the implants. This in turn can affect the efficiency of inductive power link due to its eddy current in the magnetic field (Donaldson 1992) and thus power loss. Thus, it is preferred to encapsulate the coil and electronics package using a non-conductive material. Note however, even if a non-conductive material can be used for encapsulation, hermetic sealing may still require a metallic braze line to be incorporated in the device. For example, Lichter et al. employ a Gold ABA braze line as a method of sealing two halves of a diamond hermetic capsule together (Lichter et al. 2015b) in similar fashion as shown in Fig.1

In order to respond to the above limitations, we have developed a new fabrication method of planar square spiral microcoils made using silver ABA completely embedded within non-conductive diamond. The coils have a large rectangular cross-section thus reducing resistance and increasing Q-factor. The microcoils in this work are capable of providing about $10 \mathrm{~mW}$ of transferred power across $0.51 \mathrm{k} \Omega$ at a distance of $6 \mathrm{~mm}$ which should be sufficient to power an implanted device for neural stimulation and/or recording. As the toxicity of silver ABA is an issue, we also describe a method to encapsulate the microcoil with an additional layer of diamond and test its effects on power efficiency. In addition to this, an accelerated aging test is conducted on the encapsulated microcoils. Finally, since the work described here extends upon the work of Lichter $e t$ al., it was important to evaluate the impact that an adjacent braze ring might have on inductive power transfer efficiency of a microcoil embedded in diamond. While a theoretical study for an adjacent metallic braze line is described by Donaldson N. d. N. (Donaldson 1992), predicting that power transfer efficiency will be reduced due to the braze line adjacent to the receiver coil, the impact of braze lines on encapsulated coils has not been empirically studied to our knowledge.

INSERT FIG. 1 HERE 


\section{Materials and Methods}

\subsection{Materials}

Silver ABA was used for the microcoil containing silver, copper, aluminum and titanium (Ag 92.75\%, Cu 5\%, Al 1\%, Ti 1.25\%, Wesgo Ltd.). Gold ABA containing gold, nickel and titanium (Au 96.4\%, Ni 3\%, Ti 0.3\%, Wesgo Ltd.) was utilised as the braze line material. Microcoils were embedded in polycrystalline diamond (PCD) substrates (Element 6 T100 grade). A mixture of sulfuric acid (95-97\% reagent grade, ISO) and sodium nitrate mixture was used to clean PCD substrates. Probe connection wires were made of platinum (A-M systems, Pt-Ir, $0.005^{\prime \prime}$ bare) and/or copper (Cu) and attached to the coils for measurement purposes. PCD was grown on the exposed surface of microcoils from a mixture of methane and hydrogen gas (BOC Australia) for full encapsulation. Araldite epoxy was used to cover the connection wires during the ageing test.

\subsection{Design and fabrication method of microcoils embedded in diamond}

A flow chart of the design and fabrication process of microcoils is shown in Fig. 2 (a). Planar square spiral coil trenches with different width, depth and separation between two adjacent turns were laser milled into PCD substrates to compare different coil versions. At the two ends of the spiral trench, holes were laser milled right through the PCD substrate for each sample such that the microcoils ended up as pads on the under-side of the substrate during silver brazing for connection of wires. The laser milled PCD substrates were acid boiled in a mixture of $97 \%$ sulfuric acid ( $5 \mathrm{ml})$ and sodium nitrate $(25-50 \mathrm{mg})$ for one hour. After acid boiling substrates were cleaned sequentially in acetone and distilled water. The width and height of the microcoil trench and the separation between two consecutive coil turns were measured by scanning electron microscopy (SEM; FEI Quanta, FEG 200, Fig. 2b) and optical profilometry (Fig. 2(c)). Silver ABA paste was poured into the coil trench and melted using a MTI vacuum furnace. The furnace was evacuated to a pressure of $5-6 \times 10^{-6}$ Torr and the temperature ramped up to $960{ }^{\circ} \mathrm{C}$. The samples were held at $960{ }^{\circ} \mathrm{C}$ for $10 \mathrm{~min}$ and then the temperature was ramped down to room temperature gradually. Excess silver $\mathrm{ABA}$ was polished out mechanically using a Coborn PL3 Planetary Lapping machine. SEM images were taken post cleaning. Finally connection wires were laser welded onto the pads on the under-side of the microcoils (Fig. 2(d)).

\section{INSERT FIG. 2 HERE}

\subsection{Electrical characterization method}

The electrical characterisation of microcoils is the measure of its Q-factor, DC resistance, and inductance. A 30 $\mathrm{MHz}$ frequency response analyser (AP Instruments Inc., Model 300) was used for microcoil characterisation. This analyser had a frequency range from $0.10 \mathrm{~Hz}$ to $30 \mathrm{MHz}$. The above electrical parameters were measured with respect to frequency.

\subsection{Wireless power transfer and braze line effect measurement method}

Power transfer and power receiver units were constructed according to the schematic diagram shown in Fig. 3. A power transfer unit was connected to a DC power supply (model TPS-4000). A $3 \mathrm{~cm}$ circular transmitter coil (Nucleus patient coil Z209880 manufactured by Cochlear Ltd, Fig. 3) was attached to the power transfer unit. This unit consists of a tuned circuit and integrated RF coil driver. The DC input supply voltage of the power transfer unit was 3.3 volts and input current was approximately $135 \mathrm{~mA}(135 \mathrm{mV}$ measured across $1 \Omega)$. Radio frequency (RF) waves of $4.82 \mathrm{MHz}$ were generated and tuned near to self-resonance of the receiver microcoils by a RF generator (HP Hewlett Packard, 33120A). In order to measure inductive power transfer the microcoils were placed $6 \mathrm{~mm}$ away along the axis passing through the centre of the transformer coil. The eight best fabricated microcoils were tested separately using the same receiver unit. A rectifier circuit was used to obtain output power across various loads. Input current and output voltage at different load resistances (R, Fig. 3) were measured with a multimeter (RPG, DM8100). To assess effects of brazing on efficiency, a gold braze line $(5.1 \times$ $5.1 \mathrm{~mm}$ ) fabricated on a separate diamond substrate was introduced either directly on the surface of the 
microcoil in a parallel orientation (Fig. 3b) or in a perpendicular position $0.2 \mathrm{~mm}$ away from the outer diameter of the microcoils (Fig. 3c) whilst connected to the measurement circuit.

INSERT FIG. 3 HERE

\subsection{Coil encapsulation method}

Following initial baseline measurements, an additional layer of PCD was deposited onto exposed surface of the microcoils in an Iplas microwave plasma-assisted chemical vapour deposition (CVD) system. Microcoils were seeded before PCD deposition with nanodiamond (Nano Armor) by ultra-sonication in $\sim 3-5 \mathrm{~nm}$ nanodiamond/methanol solution for 5 minutes. Compressed air was used to dry the samples. A gas mixture of $500 \mathrm{sccm}$ hydrogen and $10 \mathrm{sccm}$ methane (BOC Australia, purity 99.99\%) was used. During the growth period, the microwave power was maintained at $900 \mathrm{~W}$, gas pressure at $60 \mathrm{Torr}$ and stage temperature at $800{ }^{\circ} \mathrm{C}$. The PCD layer was grown for several hours and Elemental analysis (EDS) of the PCD film was performed to diagnose the exposure of silver through the PCD layer.

\subsection{Accelerated ageing method}

Samples were used in an accelerated ageing test. Samples were individually placed in a capped small clean glass bottle fulfilled with $0.9 \%$ medical grade sterile saline (Aerowash Sterile Sodium Chloride Eyewash Solution). The bottles were transferred to an environmental chamber (Micro Climate Benchtop Test Chamber Cincinnati Sub-Zero) kept at $85^{\circ} \mathrm{C}$. Images were recorded using SEM before and after ageing for time periods of 30 days corresponding to approximately 30 months of real time equivalent at $37^{\circ} \mathrm{C}$ in a saline environment. An aging factor $\left(\mathrm{Q}_{10}\right)$ of 2 was used for all accelerated aging calculations.

\section{Results and Discussion}

\subsection{Microcoil fabrication outcomes}

Eighteen $4.6 \times 4.6 \mathrm{~mm}$ microcoils were fabricated using four sets of parameters according the values presented in Table-1. Table-1 also provides the measured resistance and Q-factor for each of the four sets of microcoils. In order to observe the effect of depth and width of microcoils the depth $(\mathrm{h}=100 \mu \mathrm{m})$ of set 2 and width $(\mathrm{w}=80 \mu \mathrm{m})$ of set 3 were different from that of the set 1 while the outer dimension $(4.6 \mathrm{~mm})$ and number of turns $(\mathrm{N}=4)$ were same. In case of set 4 the number turns $(\mathrm{N}=20)$ was more than set $1(\mathrm{~N}=4)$ including much wider cross sectional area of turns. The results show that the Q-factor is dependent on width, depth and number of turns. The actual values of width, depth and separation between two consecutive turns presented in the table were obtained from optical profilometry images which were in most cases close to the expected values in parentheses. Generally, the separation between two consecutive turns was found to be lower than expected while the width of trench was found to be several micrometers over that of the expected values during laser milling, most likely due to the conical shape of the laser used for milling. The depth of the coil trench which also varied by several micrometers in some places was over that of the targeted depth during laser milling. There was difficulty in obtaining imaging data from the bottom of the trench for microcoil set 2 due to the small width so depth values for this set were significantly underestimated. As the eight microcoils from set 4 were superior to samples from the other sets in terms of lower DC resistance and higher Q-factor, in-depth further experiments were conducted only on this microcoil set.

Fig. 4 (a) shows an SEM image of one of the microcoils from set 4 . The bottom of the coil trench was found to be narrower than that of the top due to the focusing angle of the cutting laser. A side wall angle was typical $\leq 11$ degrees in all our samples. SEM images after polishing and cleaning showed instances of small cracks in the PCD between coil turns as shown in Fig.4 (b). In our study, the cracks did not short two consecutive turns. However, there is an inherent risk of shorting between turns negatively impacting on Q-factor if these cracks would fill with braze. These cracks might be reduced by controlling brazing temperature profiles so that PCD 
substrates do not bend during heating and by using smooth wheel surfaces during mechanical polishing. Also, lower speed polishing may reduce the appearance of cracks.

Table-1: Resistance and Q-factor (average \pm std. error) of four sets of coils embedded in diamond with several design parameters. Values in parentheses show targeted/expected parameters. *Difficulty in getting accurate depth data from this set of coils

\begin{tabular}{|c|c|c|c|c|c|c|c|}
\hline $\begin{array}{c}\text { Sets and } \\
\text { number } \\
\text { of coils }\end{array}$ & $\begin{array}{c}\text { Outer } \\
\text { diameter } \\
\text { in } \mathrm{mm}\end{array}$ & $\begin{array}{l}\text { Width (w) } \\
\qquad \mu \mathrm{m}\end{array}$ & $\begin{array}{c}\text { Depth (h) } \\
\mu \mathrm{m}\end{array}$ & $\begin{array}{c}\text { Separation } \\
\text { Between } \\
\text { turns } \mu \mathrm{m}\end{array}$ & $\begin{array}{l}\text { Number } \\
\text { of turns }\end{array}$ & $\begin{array}{l}\text { Average } \\
\text { resistance } \\
\left(\mathrm{R}_{\mathrm{DC}}\right) \Omega\end{array}$ & $\begin{array}{c}\text { maximum } \\
\text { Q-factor }\end{array}$ \\
\hline $\begin{array}{l}\text { Set } 1 \\
(n=4)\end{array}$ & 4.6 & $\begin{array}{l}31.20 \pm 1.67 \\
(21)\end{array}$ & $\begin{array}{c}35.34 \pm 0.78 \\
\text { (35) }\end{array}$ & $\begin{array}{l}62.05 \pm 1.84 \\
(70)\end{array}$ & 4 & $5.18 \pm 0.58$ & $\begin{array}{l}1.21 \pm 0.08 \\
\text { at } \sim 11 \mathrm{MHz}\end{array}$ \\
\hline $\begin{array}{l}\text { Set } 2 \\
(n=4)\end{array}$ & 4.6 & $\begin{array}{c}34.30 \pm 1.85 \\
(21)\end{array}$ & $\begin{array}{c}39.12 \pm 2.53^{*} \\
(100)\end{array}$ & $\begin{array}{c}59.80 \pm 1.53 \\
(70)\end{array}$ & 4 & $2.38 \pm 0.11$ & $\begin{array}{l}1.98 \pm 0.05 \\
\text { at } \sim 8 \mathrm{MHz}\end{array}$ \\
\hline $\begin{array}{l}\text { Set 3 } \\
(n=2)\end{array}$ & 4.6 & $\begin{array}{c}84.39 \pm 1.15 \\
(80)\end{array}$ & $\begin{array}{c}35.07 \pm 0.17 \\
(35)\end{array}$ & $\begin{array}{c}70.80 \pm 0.85 \\
(70)\end{array}$ & 4 & $1.35 \pm 0.05$ & $\begin{array}{l}2.69 \pm 0.08 \\
\text { at } 5.88 \mathrm{MHz}\end{array}$ \\
\hline $\begin{array}{l}\text { Set } 4 \\
(n=8)\end{array}$ & 4.6 & $\begin{array}{c}46.3 \pm 0.41 \\
(50)\end{array}$ & $\begin{array}{c}120.45 \pm 1.15 \\
(140)\end{array}$ & $\begin{array}{c}54.00 \pm 0.33 \\
(50)\end{array}$ & 20 & $2.25 \pm 0.05$ & $\begin{array}{l}3.87 \pm 0.23 \\
\text { at } \sim 3.2 \mathrm{MHz}\end{array}$ \\
\hline
\end{tabular}

\section{INSERT FIG. 4 HERE}

\subsection{Electrical characterization}

The Q-factors and AC resistance of the microcoils from set-4 are graphically depicted in fig. 5 with respect to frequency. The measured resistance of the microcoils gradually increased as a function of frequency (Fig. 5 (a)). The maximum value of Q-factor of the microcoils was 4.05 at $3.89 \mathrm{MHz}$ (Fig. 5b). The small variation $( \pm 0.052)$ in Q-factor and resistance $( \pm 0.33)$ provided evidence of the reproducibility in manufacturing as the temperature during brazing was better controlled than that of the other microcoil sets 1-3.

\section{INSERT FIG. 5 HERE}

\subsection{Wireless power transfer and braze line effects}

Fig. 6 (a) shows the amount of average power transfer across different load resistances from $0.51-7.51 \mathrm{k} \Omega$. The measured maximum output voltage was of 2.41 volts and an average power of $8.64 \pm 1.62 \mathrm{~mW}$ ( $\mathrm{n}=6$ coils) was obtained across a $0.51 \mathrm{k} \Omega$ load with the highest transmitted power up to $11.38 \mathrm{~mW}$. The power transfer efficiency of the microcoils as a percentage across different load resistances is shown in Fig. 6 (b). The average power transfer efficiency was $1.96 \pm 0.35 \%$ across a $0.51 \mathrm{k} \Omega$ load without the presence of any braze line. When comparing our transmitted power results to coils manufactured using lithographic techniques, we were able to transmit almost the same power with a coil of nearly half the dimensions. Also, the coils made using lithographic techniques were not able to send power beyond $4 \mathrm{~mm}$ ( $\mathrm{Li}$ et al. 2011) but our microcoils are capable to transfer power up to $6 \mathrm{~mm}$ away along the axis of the transmitter coil. Transmitted power of $10 \mathrm{~mW}$ would be sufficient for neural recording by a chip of 32 channels which consumes a total power of $5.4 \mathrm{~mW}$ (Wise 2005). This power could also be sufficient for a neuromuscular or optogenetic stimulation device (Lee 2005; Montgomery et al. 2015). Fig. 6 (c) indicates the impact of a braze line on the power efficiency for three of the eight microcoils of higher $\mathrm{Q}$ - factors with increasing distance between the braze line and microcoils. It was observed that the effect of a gold braze line oriented parallel to the microcoil did not affect power 
efficiency when placed more than $2 \mathrm{~mm}$ away from the plane of the microcoil (Fig. 6c) but could reduce power efficiency by up to $43 \%$ when placed directly on the coil $(0 \mathrm{~mm})$. However, when the braze line was placed perpendicularly to the plane of the coil $0.2 \mathrm{~mm}$ away from the outer edge, the power transfer efficiency was not affected significantly compared to the power efficiency of the coils without any braze line.

\section{INSERT FIG. 6 HERE}

\subsection{Effects of encapsulation and accelerated ageing}

Encapsulation of microcoils was performed in two stages. Firstly, a group of 4 out of 8 microcoils from set 4 were encapsulated by a PCD layer grown for $5 \mathrm{~h}$ applying the methodology described earlier. Secondly a separate group of 2 microcoils were encapsulated by the PCD layer grown for $14 \mathrm{~h}$ with the same conditions as applied for the first group. The remaining 2 microcoils were subjected to an ageing test without encapsulation. Microcoils were grouped in a random manner. Fig. 7 (a) and (b) show SEM images at two different magnifications for one of the encapsulated microcoils. As seen in the images, larger diamond crystals were found to grow on the space between coil turns while finer crystals grew over the trench. Elemental analysis (EDS) of the PCD film, revealed no silver peaks for only one of the microcoils encapsulated by PCD using a $5 \mathrm{~h}$ growth time. In contrast, both microcoils in the second group encapsulated by PCD using a $14 \mathrm{~h}$ growth time were free of silver peaks. After electrical measurements on encapsulated microcoils, an ageing test with the conditions described in methodology was conducted on all samples exhibiting full encapsulation (1 coil from the 5-hour group and both coils from the 14-hour group).

\section{INSERT FIG. 7 HERE}

The ageing test was conducted for 30 days at $85^{\circ} \mathrm{C}$ as described in the methods over 3 encapsulated and 2 nonencapsulated microcoils. Plots depicting the change in Q-factors before and after PCD growth, after an aging test and eventually after oxygen plasma treatment of the samples are shown in Fig. 7 (c), (d), (e) and (f) respectively. When performing measurements after encapsulation, it was observed that the resistance of the microcoils increased and consequently the Q-factor decreased by $38 \%$ over the 3 encapsulated samples (Fig. 7 (c), (d) and (e)). The Q - factor of the 5-hour encapsulated microcoil (Fig. 7 (c)) was found to be higher than that of the two coils in the 14-hour group (Fig. 7 (d) and Fig. 7 (e)), indicating that a thinner PCD layer may have less impact on the reduction of $\mathrm{Q}$ - factor albeit with the high risk of exposure of silver ABA. It is worth mentioning that the $\mathrm{Q}$ - factor improved to some extent after accelerated ageing of the encapsulated samples. Subsequent resistivity measurements over the grown PCD films showed that the PCD layers on the coils surface were conductive due the possible presence of graphitic material which may have caused the drop of the Qfactor. It is important that DC resistance of the microcoils remained the same, which indicates that the microcoils embedded in diamond were not changed. On the other hand, a nonconductive oxide layer may have been formed during the ageing period on the PCD, reducing the conductivity of the films to some extent which improved the Q - factor which led to oxygen plasma treatment on the PCD layer. After oxygen plasma treatment the Q - factor of PCD encapsulated coils further increased as in Fig. 7 (c, d and e) and PCD film surface became nonconductive. Thus, overall for future work it will be important to address a fine balance between the risk of silver exposure and the nonconductive PCD formation by careful periodic control of the encapsulation growth 
time and then oxygen plasma treatment for each layer corresponding to each periodic growth time of PCD on coil surface.

Somewhat surprisingly, there was no significant change in Q - factor before and after accelerated ageing of the microcoils without encapsulation (Fig. 7 (f)). The most likely explanation for this is that since silver ABA is an alloy containing silver, copper, aluminum and titanium, it may take more time to degrade compared to when using a single metal. SEM images were taken after the ageing tests but no visible changes in the diamond encapsulated samples were observed in case of $14 \mathrm{~h}$ growth. There was a tiny spot observed on PCD layer of $5 \mathrm{~h}$ growth film that appeared to be damaged. EDS test was conducted on the PCD films over the samples. EDS test on PCD films grown for $5 \mathrm{~h}$ over microcoils after accelerated ageing did indicate silver at the surface, leading to the conclusion that $5 \mathrm{~h}$ growth time was insufficient to fully encapsulate the coils. PCD layers grown for $14 \mathrm{~h}$ did not exhibit silver peaks during EDS analysis after accelerated ageing. A film thickness of 2-3 $\mu \mathrm{m}$ is typical after $14 \mathrm{~h}$ of growth under the reaction conditions used. Full encapsulation of microcoils in diamond is therefore possible provided the diamond film is grown to a sufficient thickness. Measurement of power transfer efficiency of fully encapsulated microcoils after ageing tests indicated that up to $2.64 \mathrm{~mW}$ power can be transferred over 6 $\mathrm{mm}$ of air. While $10 \mathrm{~mW}$ is ideal, $2.64 \mathrm{~mW}$ is still sufficient to power a typical neural recording device or a low power stimulator (Wattanapanitch and Sarpeshkar 2011).

Care should be taken to pour the silver ABA into the coil trench to make sure that there is no air gap which may introduce defects within the silver ABA wire in the trench. Optimum temperature control over time is very important to avoid the bending of the diamond substrate which may cause fractures during polishing. The optimum speed and surface roughness of the polishing wheel and the proper arrangement of planar placement of the microcoils on the wheel reduces fractures and any other damage of the microcoils. For hermetic sealing the PCD growth over microcoils in CVD at well below of the melting temperature of silver ABA is very beneficial. As the dimensions of the microcoil are very small, the major limitation to the power transfer efficiency comes from the loss of magnetic energy due spread of the magnetic field with respect to distance. Therefore the receiver coils should be as large as practical for the application. For instance larger coils can be used under the skin of thickness 2-8 mm (Van Mulder et al. 2017; Saurabh Vyas et al. 2015; Sharman et al. 2009) depending on body parts and health for wireless sensor networking (Carmo J.P. and Correia J.H. 2009) and miniaturized drug delivery systems (Smith et al. 2007) to control externally. In these cases a significant challenge could come from the lack of RF tuning between transreceiver coils to maximize the power transfer efficiency. The proper design of microcoils should resolve this limitation. Coupling of the coils is also extremely important. When the microcoil is out of the central axis of the transmitter coil, power transfer drops. In this work the new fabrication process includes several steps and takes approximately 10 days which, implies production in batches for commercial production.

\section{Conclusions}

We described the fabrication and electrical characterization along with the hermetic encapsulation and longevity evaluation of microcoils embedded in diamond for wireless power transfer to medical implants. The results revealed that fabrication of $4.6 \mathrm{~mm}$ diameter microcoils, embedded in diamond, was achievable and reproducible. The microcoils were able to transfer, $10 \mathrm{~mW}$ across $0.51 \mathrm{k} \Omega$ at a distance of $6 \mathrm{~mm}$ yielding a power transfer efficiency of approximately $2 \%$. This is sufficient for low powered neural recording and neuromuscular stimulation. We demonstrated that a continuous short circuit, similar in diameter and close to the microcoil reduced transfer efficiency significantly. This impacts on devices that are sealed using a continuous conducting braze line to close the packaging. Microcoils, completely encapsulated in diamond were fabricated by growing a further layer of diamond over the embedded coils. Growth of the diamond layer over the coils reduced the coil Q-factor by an average of 38\%. Nonconductive PCD may be grown using oxygen plasma treatment on PCD layers of several nanometers and continuing the PCD growth up to enough thickness (likely 2-3 microns) to encapsulate microcoils which may not change Q - factor. Encapsulated microcoils did not degrade further during 30 days of accelerated aging at $85{ }^{\circ} \mathrm{C}$ in saline $\left(30\right.$ months, real time equivalent at $37{ }^{\circ} \mathrm{C}$ ) indicating that the diamond encapsulation would be leak free over, at least, 30 months in vivo. With the drop in Q-factor, fully encapsulated microcoils were capable of receiving $2.64 \mathrm{~mW}$ of power over a distance of $6 \mathrm{~mm}$ yielding a maximum transfer efficiency of $0.65 \%$. The outer diameter of all microcoils was only $4.6 \mathrm{~mm}$ and 
therefore the technology is an attractive option for miniaturisation of wireless power delivery to future implants. As diamond is a hard, hermetic, biopermanent and biocompatible material, these microcoils are promising for long-term medical implants.

\section{Acknowledgements}

Authors gratefully acknowledge Rodney Millard his support of this work during the electrical characterization of the microcoils and Owen Burns for helping conduct the ageing tests. This research and KS were supported by an Australian Research Council (ARC) DECRA grant DE130100922. DJG is supported by the National Health and Medical Research Council (NHMRC) of Australia, grant GNT1101717. MNS is supported by the National Health and Medical Research Council (NHMRC) of Australia, grant GNT1063093. The Bionics Institute acknowledges the support received from the Victorian Government through its Operational Infrastructure Program for this work. Imaging was conducted at the Melbourne Advanced Microscopy Facility housed within Bio21 at The University of Melbourne.

\section{References}

Ahnood, A., Escudie, M.C., Cicione, R., Abeyrathne, C.D., Ganesan, K., Fox, K.E., Garrett, D.J., Stacey, A., Apollo, N.V., Lichter, S.G., Thomas, C.D.L., Tran, N., Meffin, H., Prawer, S., Biomed. Microdevices 17(3) 1-11 (2015)

Amato, M., Dalena, F., Coviello, C., De Vittorio, M., Petroni, S., Microelectronic Engineering 111, 143-148 (2013)

Baj-Rossi, C., Kilinc, E.G., Ghoreishizadeh, S.S., Casarino, D., Jost, T.R., Dehollain, C., Grassi, F., Pastorino, L., De Micheli, G., Carrara, S., Biomedical Circuits and Systems Conference (BioCAS), 2013 IEEE, pp. 166-169 (2013)

Bongrain, A., Bendali, A., Sorgues, G.L., Rousseau, L.O., Yvert, B., Scorsone, E., Bergonzo, P., Cau, S., Diamond-based technology dedicated to micro electrode arrays for neuronal prostheses. Design, Test, Integration and Packaging of MEMS/MOEMS (DTIP), 2011 Symposium on, pp. 378-384, IEEE, (2011)

Broers, A.N., Philosophical Transactions of the Royal Society of London A: Mathematical, Physical and Engineering Sciences 353(1703), 291-311 (1995)

Cavuoto, J., The Market for Neurotechnology: 2012-2016. Neurotech Reports, 1-345 (2011)

Chen, P.-J., Rodger, D.C., Saati, S., Humayun, M.S., Tai, Y. C., Journal of Microelectromechanical Systems, 17(6), 1342-1351 (2008)

Clark, G., Springer Science \& Business Media, New York, p. 459 (2003)

Carmo J.P. and Correia J.H., Microelectronics Journal, 40, 1746-1754 (2009)

Donaldson, N.d.N., Med Biol Eng Comput 30(1), 63-68 (1992)

Donaldson, P.E., 1976. The encapsulation of microelectronic devices for long-term surgical implantation. IEEE Trans. Biomed. Eng. (4), 281-285 (1976)

Ganesan, K., Invest. ophthalmol vis. sci. 55(13), 1806 (2014)

Ganesan, K., Garrett, D., Ahnood, A., Shivdasani, M., Tong, W., Turnley, A., Fox, K., Meffin, H., Prawer, S., Biomaterials 35(3), 908-915 (2014)

Garrett, D.J., Ganesan, K., Stacey, A., Fox, K., Meffin, H., Prawer, S., J Neural Eng 9, 1 (2012)

Hadjinicolaou, A.E., Leung, R.T., Garrett, D.J., Ganesan, K., Fox, K., Nayagam, D.A.X., Shivdasani, M.N., Meffin, H., Ibbotson, M.R., Prawer, S., O'Brien, B.J., Biomaterials 33(24), 5812-5820 (2012)

Jow, U.-M., Ghovanloo, M., IEEE Trans. Biomed Circuits and Syst. 1(3), 193-202 (2007)

Kadefors, R., Kaiser, E., Petersén, I., IEEE Trans. Biomed. Eng. (3), 177-183 (1969)

Kirsten, S., Uhlemann, J., Braunschweig, M., Wolter, K.J., Electronics Technology (ISSE), 35th International Spring Seminar on, pp. 123-127. IEEE, (2012)

Ko, W.H., Liang, S.P., Fung, C.D., Med Biol Eng Comput 15(6), 634-640 (1977)

Lee, S.Y.L.a.S.C., IEEE T Circuits Syst-I: Regular Papers 52(12), 2526-2538 (2005)

Lee, S.W., Min, K.S., Jeong, J., Kim, J., Kim, S.J., IEEE Trans. Biomed. Eng. 58(8), 2255-2263 (2011)

Li, W., Kabius, B., Auciello, O., Engineering in Medicine and Biology Society (EMBC), 2010 Annual International Conference of the IEEE, pp. 6237-6242. IEEE, (2010)

Li, W., Rodger, D.C., Pinto, A., Meng, E., Weiland, J.D., Humayun, M.S., Tai, Y.-C., Sensors and Actuators A: 
Physical 166(2), 193-200 (2011)

Lichter, S.G., Escudié, M.C., Stacey, A.D., Ganesan, K., Fox, K., Ahnood, A., Apollo, N.V., Kua, D.C., Lee,

A.Z., McGowan, C., Biomaterials 53, 464-474 (2015a)

Lichter, S.G., Escudie, M.C., Stacey, A.D., Ganesan, K., Fox, K., Ahnood, A., Apollo, N.V., Kua, D.C., Lee,

A.Z., McGowan, C., Saunders, A.L., Burns, O., Nayagam, D.A.X., Williams, R.A., Garrett, D.J.,

Meffin, H., Prawer, S., Biomaterials 53, 464-474 (2015b)

Martelli, D., Yao, S.T., Mancera, J., McKinley, M.J., McAllen, R.M., Am J Physiol-Reg I 307(9), R1085-R1091 (2014)

Maturana, M.I., Apollo, N.V., Hadjinicolaou, A.E., Garrett, D.J., Cloherty, S.L., Kameneva, T., Grayden, D.B., Ibbotson, M.R., Meffin, H., Plos Comput Biol 12 (4), 1-26 (2016)

Montgomery, K.L., Yeh, A.J., Ho, J.S., Tsao, V., Iyer, S.M., Grosenick, L., Ferenczi, E.A., Tanabe, Y., Deisseroth, K., Delp, S.L., Nat methods. 12 (10), 969-74 (2015)

Nayagam, D.A.X., Durmo, I., McGowan, C., Williams, R.A., Shepherd, R.K., Jove-J Vis Exp, 96 (2015)

Neagu, C., Jansen, H., Smith, A., Gardeniers, J., Elwenspoek, M., Sensors and Actuators A: Physical 62(1), 599-611 (1997)

Oxley, T., Opie, N., John, S., Rind, G., Ronayne, S., Wheeler, T., Judy, J., McDonald, A., Dornom, A., Lovell, T.J.H., Steward, C., Garrett, D., Moffat, B., Lui, E., Yassi, N., Campbell, B.C.V., Wong, Y., Fox, K., Nurse, E., Bennett, I., Bauquier, S., Liyanage, K., van der Nagel, N.R., Perucca, P., Ahnood, A., Gill, K., Yan, B., Churilov, L., French, C., Desmond, P., Horne, M., Kiers, L., Prawer, S., Davis, S., Burkitt, A., Mitchell, P., Grayden, D., May, C., O'Brien, T., 2016. Minimally invasive endovascular stent-electrode array for high-fidelity, chronic recordings of cortical neural activity. Nat Biotechnol 34(3), 320-327 (2016)

Qian, K., Malachowski, K., Fiorini, P., Velenis, D., de Beeck, M.O., Van Hoof, C., Engineering in Medicine and Biology Society, EMBC, 2011 Annual International Conference of the IEEE, pp. 7674-7677 (2011)

Shepherd, R.K., Shivdasani, M.N., Nayagam, D.A., Williams, C.E., Blamey, P.J., Trends in biotechnology 31(10), 562-571 (2013)

Shivdasani, M., Invest. ophthalmol. vis. sci. 54(15), 1029 (2013)

Saurabh Vyas, Jon Meyerle, Philippe Burlina, Computers in Biology and Medicine 57, 173-181 (2015)

Sharman A. M., Olga Kirmi and Philip Anslow, Seminars in Ultrasound, CT, and MRI, 30 (6), $452-464$ (2009)

Smith S., Tang T.B., Terry J.G., Stevenson J.T.M., Flynn B.W., Reekie H.M., Murray A.F., Gundlach A.M., Renshaw D., Dhillon B., Ohtori A., Inoue Y. and Walton A.J., IET Nanobiotechnol., 1 (5), 80-86 (2007)

Tracey, K.J., Nature 420(6917), 853-859 (2002)

Van Mulder T.J.S., de Koeijer M., Theeten H., Willems D., Van Damme P., Demolder M., De Meyer G., Beyers K.C.L., Vankerckhoven V., Vaccine 35, 1810-1815 (2017)

Wattanapanitch, W., Sarpeshkar, R., IEEE Trans. Biomed. Circuits and Syst. 5(6), 592-602 (2011)

Wise, R.O.a.K., IEEE J. Solid State Circuits 40 (12), 2796-2804 (2005)

Zhu, M., Chung, D., J Electron mater 23(6), 541-549 (1994) 


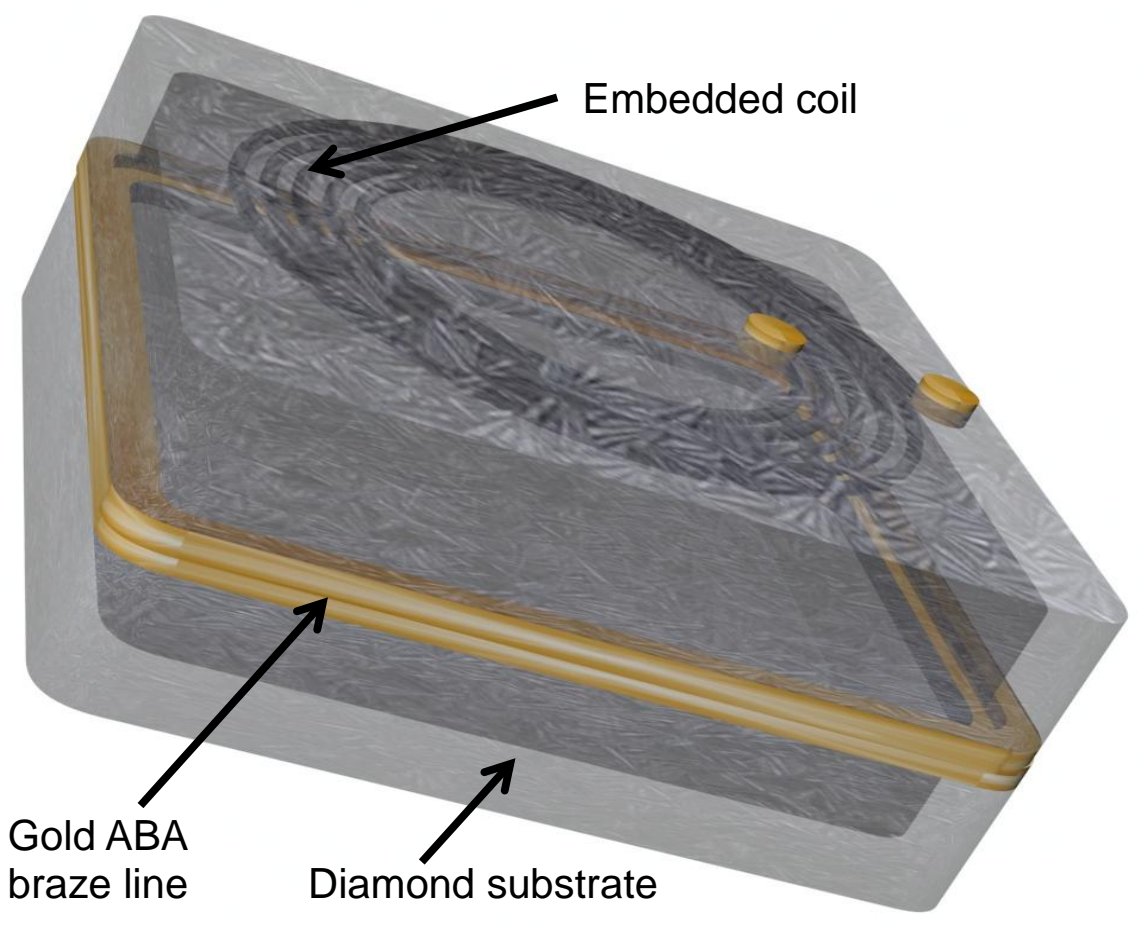

Fig.1 The schematic diagram of an embedded coil in diamond where the coil is hermetically sealed using laser welding of gold ABA braze lines. 

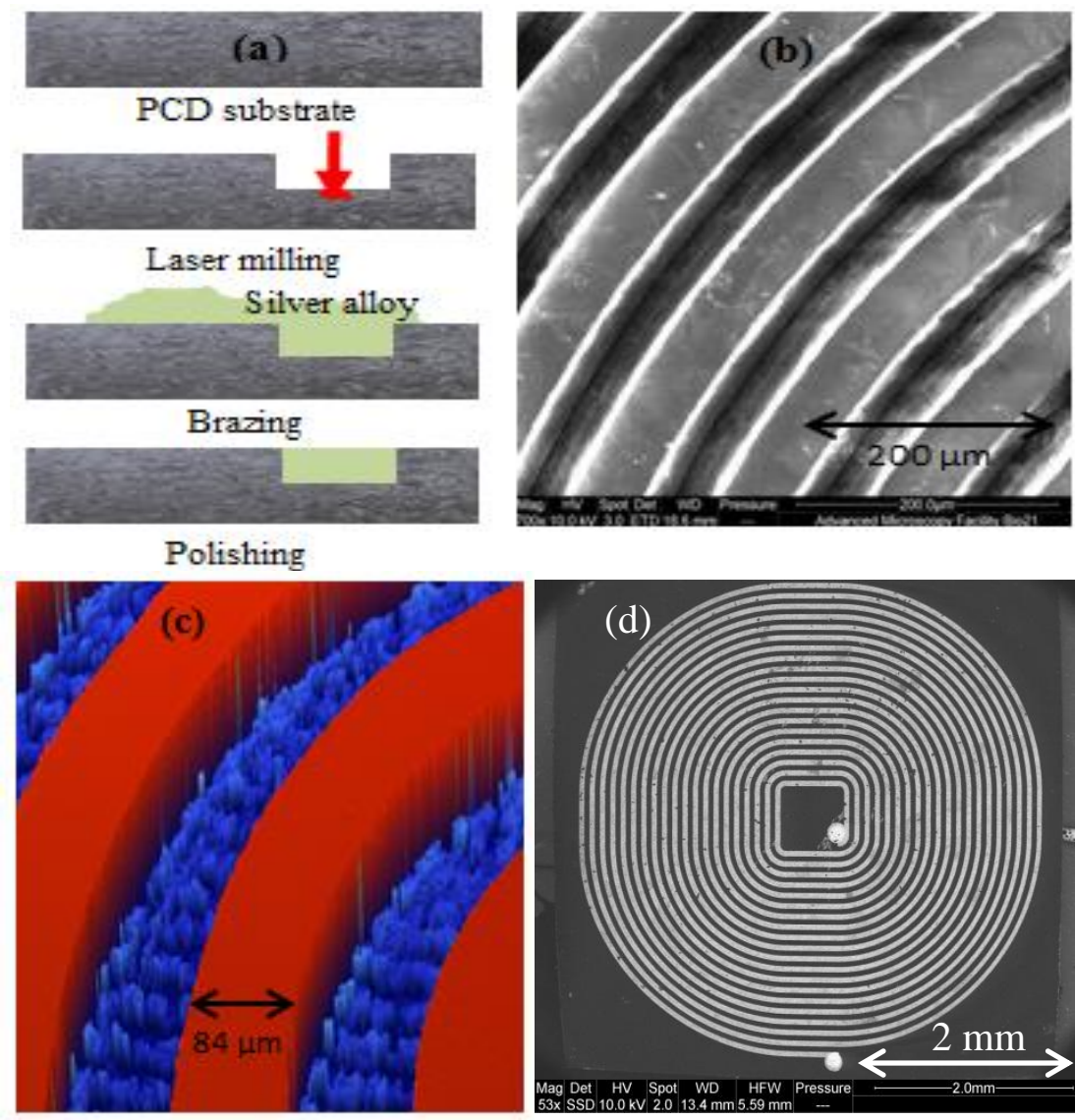

Fig. 2 (a) Sequence of fabrication process (b) SEM of coil trenches and (c) Optical profilometer image of coil trenches (bottom of the trench is in blue) and (d) Microscopic image of a $4.6 \times 4.6 \mathrm{~mm}$ coil with 20 turns of silver ABA after fabrication 


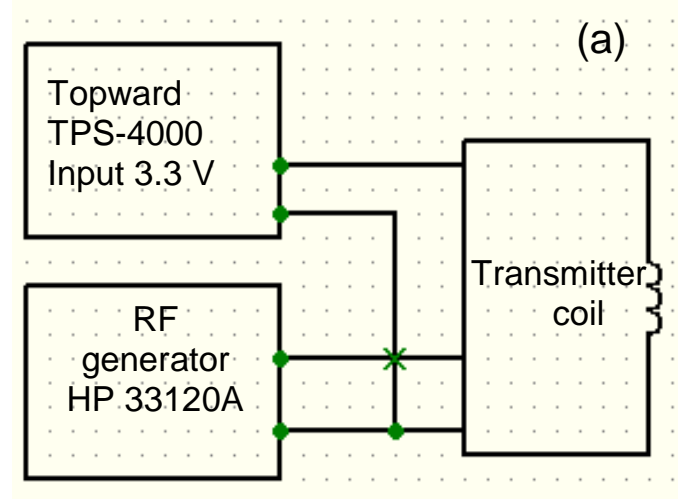

Transmitter unit

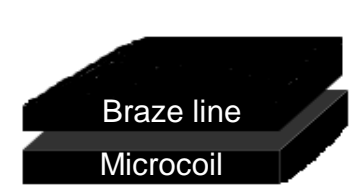

(b)

(a)

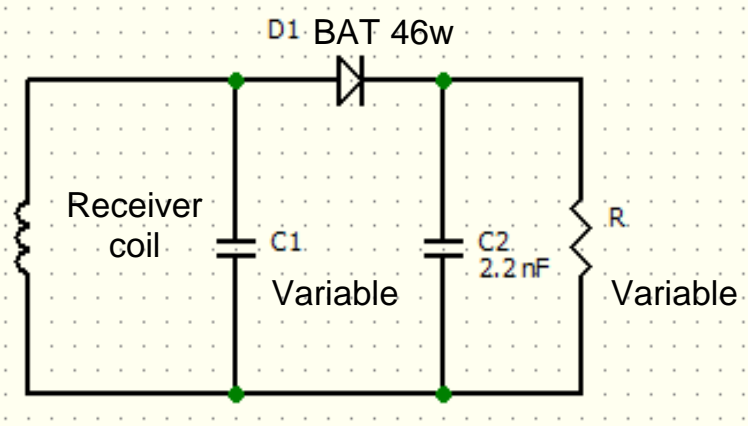

\section{Receiver unit}

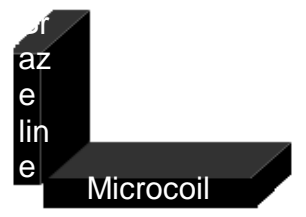

(c)

Fig. 3 Schematic diagrams: (a) circuit of transceiver unit, (b) parallel position of gold braze line to the plane of microcoil and (c) perpendicular position of gold braze line to the plane of the microcoil. 

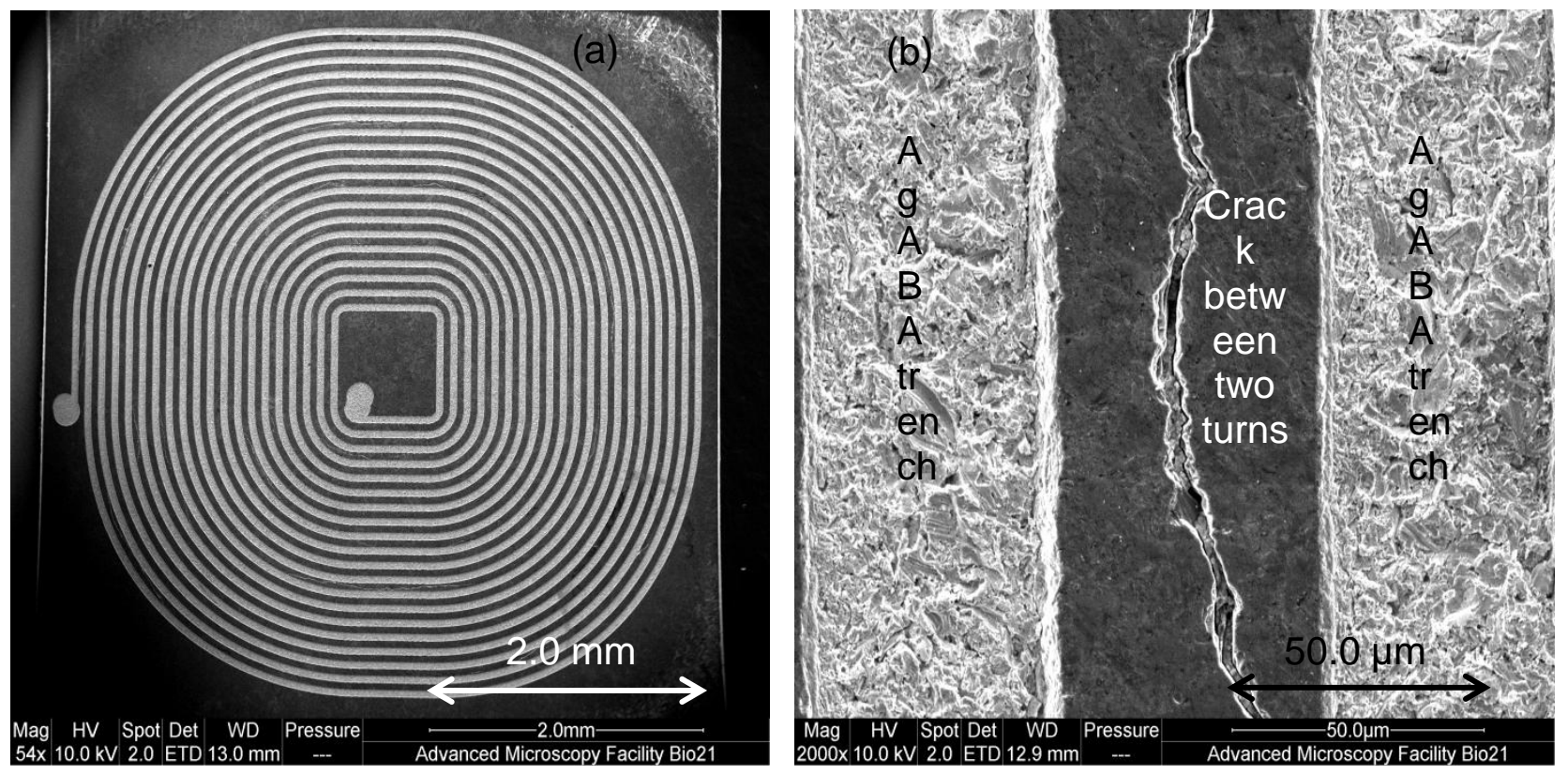

Fig. 4 (a) Top view SEM image of a microcoil, (b) SEM image of cracks on PCD between two turns 

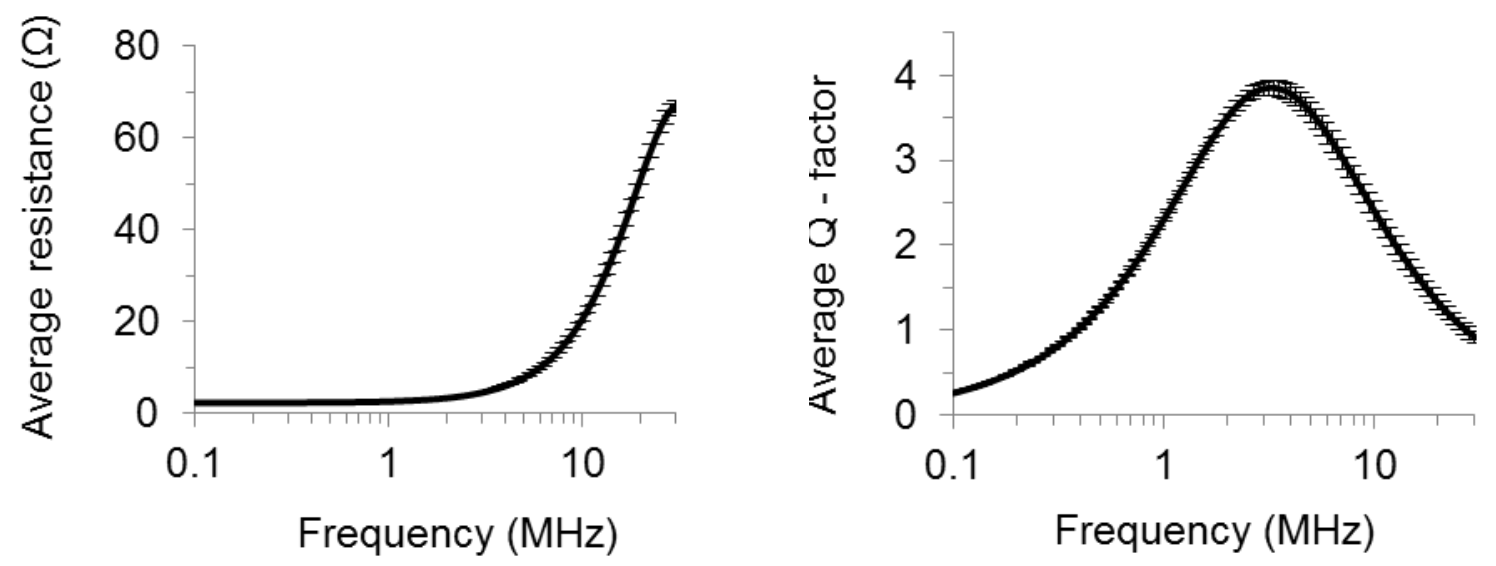

Fig. 5 (a) Average resistance and (b) Average Q-factor of the eight microcoils from set 4. X-axes are in log scale. 

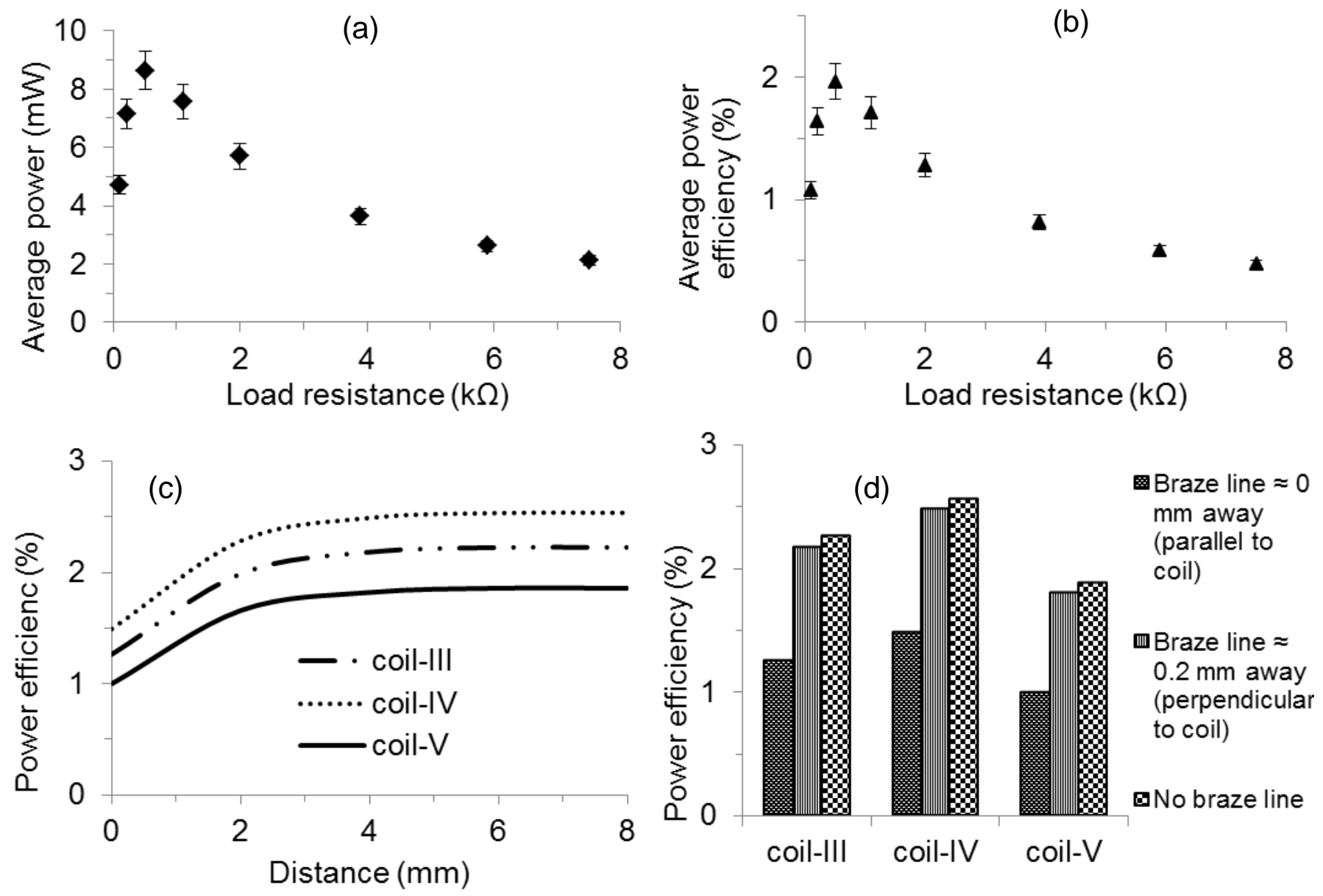

Fig. 6 (a) Transmitted average power and (b) average power efficiency, plotted against load resistance for the $4.6 \mathrm{~mm}$ diameter coils $(n=6)$ described in Table 1 from set 4 at a distance of $6 \mathrm{~mm}$ between the transmitter and receiver coil. (c) Shows the impact of a parallel gold, braze line $(5.1 \times 5.1 \mathrm{~mm})$ on power transfer efficiency of the three highest Q-factor microcoils taken from set 4,. The plots show the change in power efficiency (across $0.51 \mathrm{k} \Omega$ ) of the microcoils with increasing distance of the braze line. (d) Shows a comparison of power transfer efficiency for the same three coils as (c) between a braze ring parallel to the coil and a braze line placed $0.2 \mathrm{~mm}$ away from the outer edge in a perpendicular orientation with respect to without any braze line. 


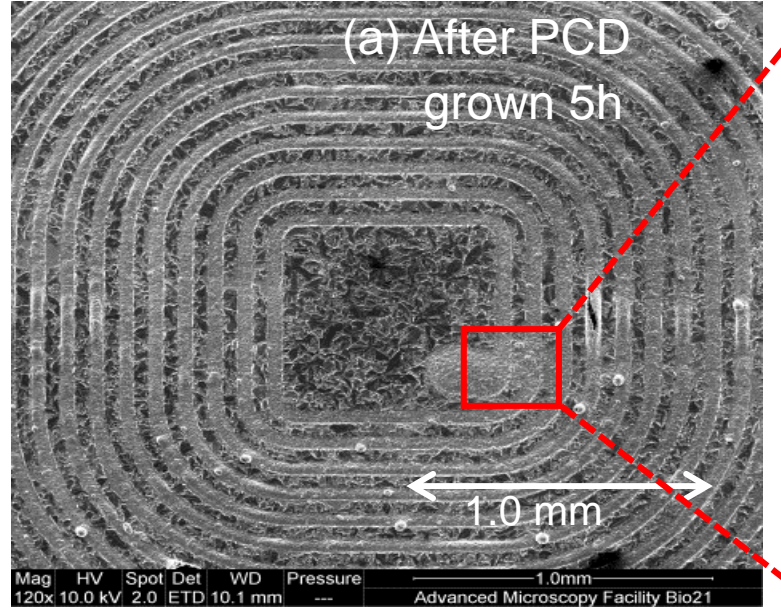

PCD grown for $5 \mathrm{~h}$

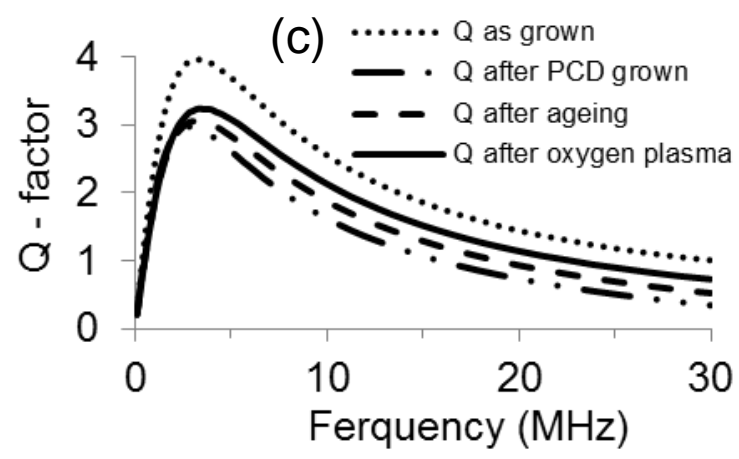

PCD grown for $14 \mathrm{~h}$

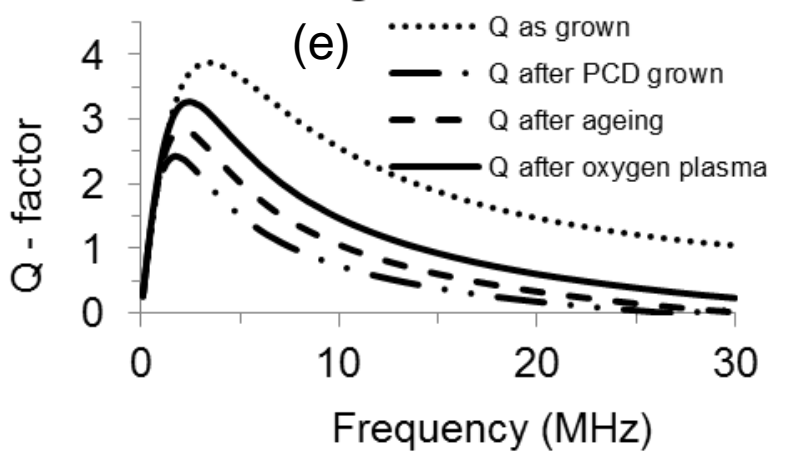

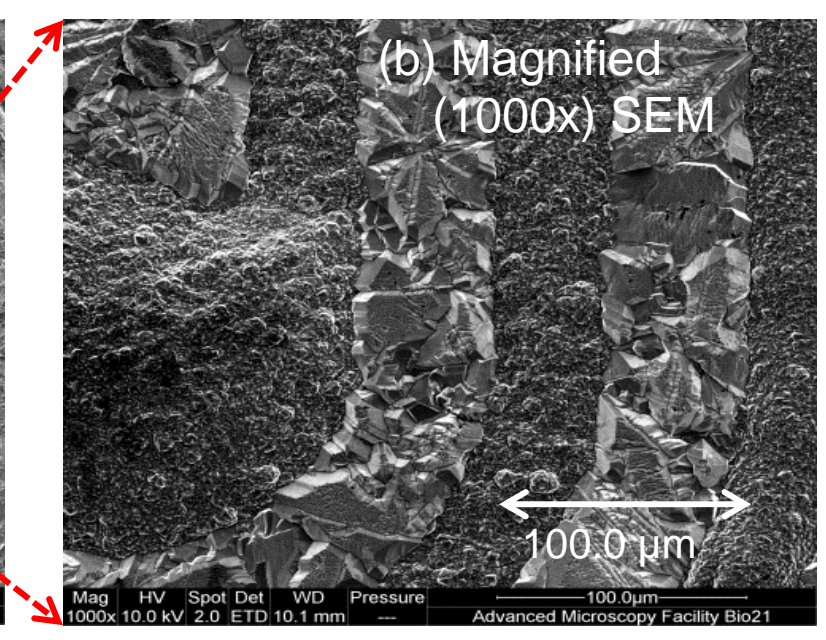

PCD grown for $14 \mathrm{~h}$

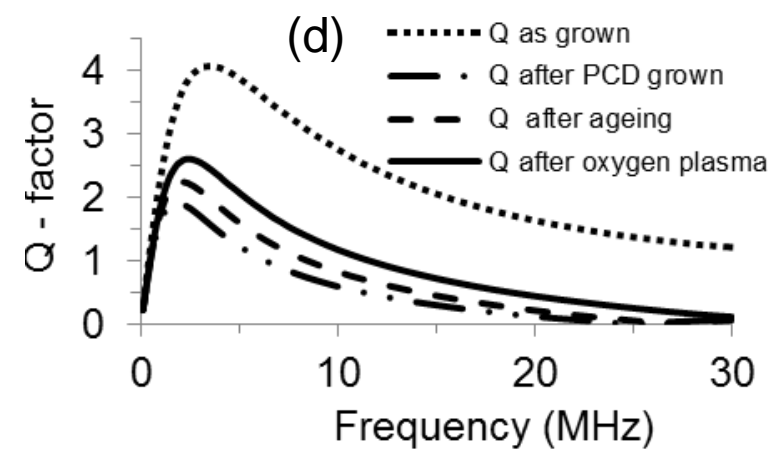

Without PCD

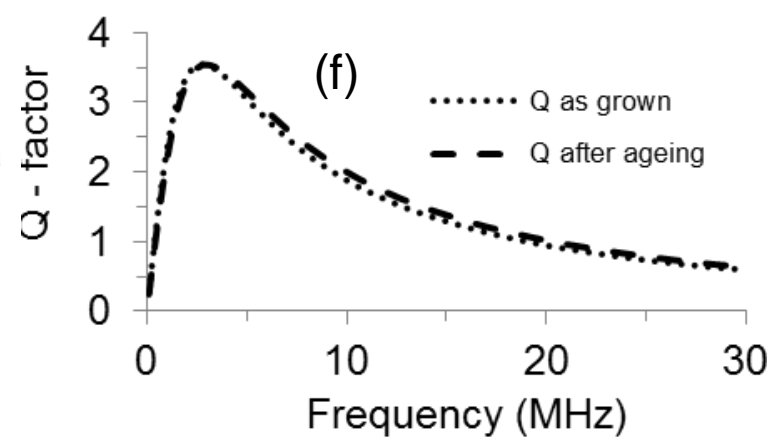

Fig. 7 (a) SEM image (top view) of a microcoil after PCD growth on the exposed surface, (b) Magnified (1000x) SEM image of the red box in the Fig. (a). Figures c-f show the change in Qfactor for samples before and after PCD growth, , after accelerated aging and after oxygen plasma treatment respectively. The PCD growth times for the samples were (c) $5 \mathrm{~h},(\mathbf{d}) \&(\mathbf{e}) 14 \mathrm{~h}$ and (f) shows the data corresponding to one of the two samples where the silver coil was aged without PCD growth. 